\title{
Erratum to: Soy intake and risk of type 2 diabetes in Chinese Singaporeans
}

\author{
Noel T. Mueller $\cdot$ Andrew O. Odegaard \\ Myron D. Gross • Woon-Puay Koh • \\ Mimi C. Yu • Jian-Min Yuan $\cdot$ Mark A. Pereira
}

Published online: 11 December 2011

(C) Springer-Verlag 2011

\section{Erratum to: Eur J Nutr}

DOI 10.1007/s00394-011-0276-2

The correct title should read "Soy intake and risk of type 2 diabetes in Chinese Singaporeans".

The article title is published incorrectly in the original publication.

The online version of the original article can be found under doi: 10.1007/s00394-011-0276-2.

N. T. Mueller $(\bowtie) \cdot$ A. O. Odegaard · M. D. Gross .

J.-M. Yuan · M. A. Pereira

Division of Epidemiology and Community Health,

University of Minnesota, 1300 South 2nd St.,

Suite 300, Minneapolis, MN 55454, USA

e-mail: mue10266@umn.edu

\section{W.-P. Koh}

Department of Epidemiology and Public Health, Yong Loo Lin

School of Medicine, National University of Singapore,

Singapore, Singapore

M. C. Yu · J.-M. Yuan

The Masonic Cancer Center, University of Minnesota,

Minneapolis, MN, USA 